\title{
Transient Stability Simulation of 33 kV Power Grid
}

\author{
Nader Barsoum, Nadira Zulkeffley, Myjessie Songkin \\ Department of Electrical and Electronics Engineering, Faculty of Engineering, Universiti Malaysia Sabah (UMS), Kota Kinabalu \\ Sabah, Malaysia \\ Email: nnb3@hotmail.com,nadirazulkeffley@gmail.com, myjessies@sesb.com.my
}

How to cite this paper: Barsoum, N. Zulkeffley, N. and Songkin, M. (2018) Transient Stability Simulation of $33 \mathrm{kV}$ Power Grid. Energy and Power Engineering, 10, 301-318.

https://doi.org/10.4236/epe.2018.106019

Received: June 2, 2018

Accepted: June 25, 2018

Published: June 28, 2018

Copyright (c) 2018 by authors and Scientific Research Publishing Inc. This work is licensed under the Creative Commons Attribution International License (CC BY 4.0).

http://creativecommons.org/licenses/by/4.0/

\begin{abstract}
An example of Sandakan power grid problem is presented in this paper. Sandakan is a suburb in east coast of Sabah state of Malaysia. Stability problem occurs due to the increase in load demand, lack of generation sources and inadequate supply. The tripping disturbances occur frequently in the network which is contributing to voltage instability. In this paper dynamics stability of $33 \mathrm{kV}$ power grid as related to Sandakan network is analyzed and simulated. The analysis is completed by modelling the network data in Power System Simulation for Engineering (PSS/E) software and simulate the transient stability of generator, exciter and governor during a three phase fault occurs on a far and close distance from a bus, and determine the critical clearing time as well as swing curve of rotor angle. The output values of electrical power, machine speed, rotor angle and bus voltage are observed.
\end{abstract}

\section{Keywords}

Transient Stability, PSS/E, Load Flow, Generator, Exciter, Governor, Critical Clearing Time

\section{Introduction}

Generally, a power system under normal operating conditions may face a contingency such as transmission element outages, generator outages, loss of transformer, and sudden change in the load or faults [1]. Transient is an event occurs when a power system subjected to large disturbances under dynamic stability [2]. Disturbances include loss of synchronism, loss of generation, loss of load in transformers or faults on transmission element and lines. Transient stability is one of major analysis in the power system in order to ensure the system stability to withstand a major disturbance and to ensure that the transmission system is 
operated safely, steady state and contingency analysis must be performed [7].

The round rotor generator model (GENROU) represents as solid rotor generator at sub-transient level is used to produce machine rotor angle for transient stability. Rotor angle has the ability of interconnecting the synchronous machines with power system to remain in synchronism. Stability is related to generator electromagnetic torque and mechanical torque which cause the rotor to accelerate or decelerate [1]. Voltage stability is related to change in the load. This stability is the ability of a power system to maintain steady voltages at all busses from a given initial condition after being subjected to a disturbance [6]. Voltage instability increases by load demand or change in system condition which cause the incontrollable drop in voltage. With abnormal low voltage it is lead to voltage collapse also contributes to blackout of the grid system [2]. The problems were reported with power flow and contingency in terms of blackout after main grid supply outages with overload and high fault current on distribution system [4] [6]. Critical clearing time is known as maximum time duration that a fault may occurs in a power system without loss of stability. There are three type of fault condition which pre-fault system conditions, fault structure (type and location) and post fault conditions [3]. The three-phase fault is the most serious kind of fault and its critical clearing time can reflect the transient stability of power system. Critical clearing time (CCT) can be obtained by trial and error method [4].

Synchronous generator is the source of electrical energy where in the generator the mechanical energy usually transformed into electrical energy. This transformation is provided by excitation of synchronous generator and is regulated by excitation system. An IEEE Type 2 Excitation System (IEEET2) and turbine governor such as Gas Turbine (GAST) and Turbine IEEE Type 1 Speed Governing Model (IEEEG1) are used.

Generator excitation is defined as generator output voltage and output reactive power. It means that the excitation is actually output energy of generator regulation and this can impact the stability of the power system. The use of an excitation system is for maintaining the output voltage, control the shaft's speed and enhancing the generator performance.

In this paper, PSS/E will be used for characterizes the power system transmission network and generation performance for both load flow analysis and transient analysis [5]. All the sources referred from the books, articles, research papers and journals.

\section{Modelling the Network in PSS/E}

The following information needed for modelling the network. This includes bus data, branch data, load data, generator data and transformer data. These data are saved in data.sav file in PSS/E and are given in the Appendix. All data and parameters are taken from Sandakan power grid system.

The power network consists of 26 buses, 8 generators and 22 loads. The highest 
bus base is $33 \mathrm{kV}$ and the lowest is $6.6 \mathrm{kV}$. Figure 1 represents the existing network.

\section{Transient Stability Analysis}

In order to achieve stability of power system, load flow study is an important tool that gives a numerical solution. In power flow analysis a per-unit system is used for voltage magnitudes and angles, real and reactive powers.

In conducting transient analysis, there are three machine model must be taken into account such as generator, exciter and governor. These are as follows:

- Round Rotor Generator Model (GENROU)

- Exciter IEEE Type 2 Excitation System (IEEET2)

- Turbine Governor GAST

- Turbine IEEE Type 1 Speed Governing Model (IEEEG1)

Tables 1-4 show the parameters of the above models

\section{Load Flow Result}

The diagram Figure 1 is the operation of load flow for 26 buses divided into 1 slack bus which is BN_11 as a swing bus. The transient stability analysis requires the solution of a system of coupled non-linear differential equation. Load flow simulation on PSS/E using Newton Raphson gives the following values in Tables $5-7$.

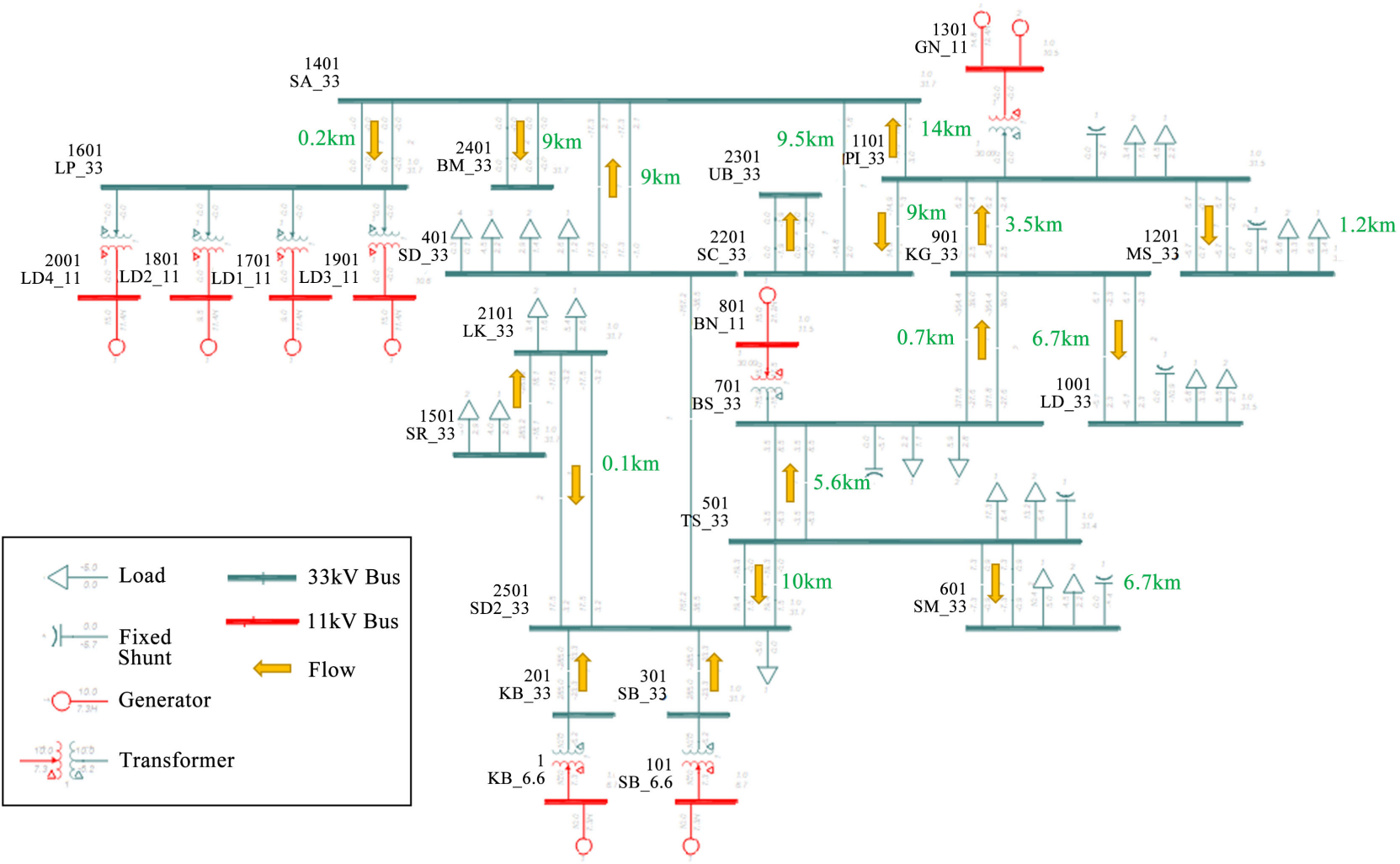

Figure 1. Sandakan power grid model in PSS/E. 
Table 1. Parameters of genrou genrator model.

\begin{tabular}{ccccc}
\hline & & \multicolumn{3}{c}{ Con Value } \\
\hline Con Description & KB_6.6 SB_6.6 & BN_11 & GN_11 & LD1_11, LD2_11, LD3_11, LD4_11 \\
T'do (>0) & 2.10 & 5.70 & 6.50 & 4.90 \\
T"do (>0) & 0.05 & 0.05 & 0.05 & 0.05 \\
T'qo (>0) & 1.10 & 0.75 & 0.75 & 0.50 \\
T"qo (>0) & 0.19 & 0.05 & 0.05 & 0.05 \\
H, inertia & 1.757 & 4.68 & 6.70 & 3.19 \\
D, Speed Damping & 0.19 & 0.00 & 0.00 & 0.00 \\
Xd & 1.91 & 2.01 & 2.02 & 1.35 \\
Xq & 1.89 & 1.898 & 1.92 & 0.79 \\
X"d & 0.20 & 0.30 & 0.189 & 0.39 \\
X"q & 1.02 & 0.60 & 0.30 & 0.30 \\
X"d = X"q & 0.15 & 0.185 & 0.28 & 0.12 \\
Xl & 0.11 & 0.10 & 0.10 & 0.10 \\
S(1, 0) & 0.13 & 0.08 & 0.06 & 0.35 \\
S(1, 2) & 0.39 & 0.35 & 0.19 & \\
\hline & & & & 0.19 \\
\hline
\end{tabular}

Table 2. Parameters of IEEET2 exciter model.

\begin{tabular}{cccc}
\hline Con Description & KB_6.6 and SB_6.6 & BN_11 and GN_11 & $\begin{array}{c}\text { LD1_11, LD2_11, } \\
\text { LD3_11, LD4_11 }\end{array}$ \\
\hline TR (sec) & 0.02 & 0.00 & 0.00 \\
KA & 13.40 & 200.00 & 300.00 \\
TA (sec) & 0.00 & 0.50 & 0.50 \\
VRMAX or zero & 0.00 & -2.60 & -2.60 \\
VRMIN & 6.10 & 2.70 & 10.00 \\
KE or zero & 1.00 & 1.00 & 1.05 \\
TE (>0) (sec) & 0.20 & 1.00 & 0.10 \\
KF & 0.29 & 0.10 & 0.035 \\
TF1 $(>0)($ sec $)$ & 1.40 & 0.035 & 0.068 \\
TF2 (>0) & 1.00 & 0.68 & 0.70 \\
E1 & 0.00 & 0.00 & 0.00 \\
SE (E1) & 0.21 & 0.00 & 0.00 \\
E2 & 1.00 & 0.00 & 0.00 \\
SE (E2) & 0.39 & 0.00 & 0.00 \\
\hline
\end{tabular}


Table 3. Parameters of GAST turbine model.

\begin{tabular}{cc}
\hline Con Description & GN_11 \\
\hline $\mathrm{R}$ & 0.05 \\
$\mathrm{~T} 1$ & 0.40 \\
$\mathrm{~T} 2$ & 0.10 \\
$\mathrm{~T} 3$ & 2.00 \\
$\mathrm{AT}$ & 1.00 \\
$\mathrm{KT}$ & 2.00 \\
VMAX & 0.80 \\
VMIN & 0.417 \\
DTRUB & 0.00 \\
\hline
\end{tabular}

Table 4. Parameters of IEEEG1 governor model.

\begin{tabular}{ccc}
\hline Con Description & BN_11 & LD1_11, LD2_11, LD3_11, LD4_11 \\
\hline K & 10.00 & 18.00 \\
T1 & 0.05 & 20.00 \\
T2 & 0.00 & 7.30 \\
T3 & 0.25 & 0.80 \\
U0 & 0.30 & 1.00 \\
UC & -0.30 & -1.00 \\
PMAX & 0.70 & 0.80 \\
PMIN & 0.36 & -0.05 \\
T4 & 0.10 & 0.01 \\
T5 & 0.45 & 0.10 \\
T6 & 0.00 & 0.10 \\
T7 & 0.00 & 0.10 \\
K1 & 0.33 & 1.00 \\
K2 & 0.00 & 0.00 \\
K3 & 0.67 & 0.00 \\
K6, K7, K8 & 0.00 & 0.00 \\
\hline & &
\end{tabular}

Table 5. Swing bus summary.

\begin{tabular}{cccccccc}
\hline & \multicolumn{3}{c}{ MW } & \multicolumn{3}{c}{ MVar } \\
\hline Bus Name & Base (kV) & Pgen & Pmax & Pmin & Qgen & Qmax & Qmin \\
KB_6.6 & 6.6 & 24.7 & 10.0 & 0.0 & 4.8 & 7.3 & 0.5 \\
SB_6.6 & 6.6 & 25.1 & 10.0 & 0.0 & 7.1 & 7.3 & 0.5 \\
BN_11 & 11 & 27.8 & 20.0 & 0.0 & 7.4 & 21.2 & -5.2 \\
GN_11 & 11 & 4.6 & 19.0 & 10.0 & 2.3 & 12.4 & -7.3 \\
\hline
\end{tabular}


Continued

\begin{tabular}{llllllll}
\hline LD1_11 & 11 & 7.5 & 15.0 & 8.0 & 2.4 & 11.4 & -8.5 \\
LD2_11 & 11 & 7.5 & 15.0 & 8.0 & 2.4 & 11.4 & -8.5 \\
LD3_11 & 11 & 7.5 & 15.0 & 8.0 & 2.4 & 11.4 & -8.5 \\
LD4_11 & 11 & 7.5 & 15.0 & 8.0 & 2.4 & 11.4 & -8.5 \\
\hline
\end{tabular}

Table 6. Voltage performance under normal conditions (Pre-Disturbance).

\begin{tabular}{cc}
\hline Voltage Level & $\%$ Variation \\
\hline $415 \mathrm{~V}$ and $240 \mathrm{~V}$ & $-10 \%$ and $+5 \%$ \\
$6.6 \mathrm{kV}, 11 \mathrm{kV}, 22 \mathrm{kV}, 33 \mathrm{kV}$ & $\pm 5 \%$ \\
$132 \mathrm{kV}$ and $275 \mathrm{kV}$ & $-5 \%$ and $+10 \%$
\end{tabular}

Table 7. Voltage performance under contingency conditions (Post-Fault).

\begin{tabular}{cc} 
Voltage Level & $\%$ Variation \\
\hline $415 \mathrm{~V}$ and $240 \mathrm{~V}$ & $\pm 10 \%$ \\
$6.6 \mathrm{kV}, 11 \mathrm{kV}, 22 \mathrm{kV}, 33 \mathrm{kV}$ & $+10 \%$ and $-10 \%$ \\
$132 \mathrm{kV}$ and $275 \mathrm{kV}$ & $\pm 10 \%$ \\
\hline
\end{tabular}

Table 5 shows the swing bus BN_11 holds the highest real power generation, Pgen is 27.8 MW and reactive power generation, Qgen is 7.4 MVar. This swing bus is a special generator bus serving as the reference bus. The steady-state supply voltage limits applicable for the pre-disturbance and post-fault state defined in Table 6 and Table 7. These variations of voltages are normally applied for pre and post fault

\section{Bus Voltage before and after Load Flow Simulation}

Table 8 shows all the voltages before load flow analysis are under normal condition which are not exceed than 105\% (overvoltage) and not below 95\% (under-voltage). Thus, the grid does not have any critical busses.

These parameters are found from Sandakan power grid of 26 buses. Load flow increases the voltage bus as shown.

\section{Transient Stability Result}

The transient stability analysis approach by applying a fault on a bus and run the simulation from time $=1$ until time $=$ breaker open. Based on the Sandakan grid's simulation in PSS/E, it can be seen from Figure 2 that all the machines in the system are in good initial condition.

The data from channel output file in PSS/E of Sandakan grid such as swing curve of rotor angle, impulse response of shaft speed, electrical power and bus voltage are plotted in Figures 3-9. 


\subsection{Generator}

In the normal state, the machines in a power system network operate at equilibrium corresponding to the mechanical power input, $\mathrm{Pm}$ being equal to the electrical power output, Pe. When a fault occurs in the system at time $=1.0$ seconds, the mechanical power input become greater than the electrical power output $(\mathrm{Pm}>\mathrm{Pe})$, then the speed of the machines increase as it will accelerate the rotor.

Table 8. Voltage performance before and after load flow.

\begin{tabular}{|c|c|c|c|c|c|c|c|}
\hline & & & \multicolumn{2}{|c|}{ Before load flow } & \multicolumn{2}{|c|}{ After load flow } & \\
\hline $\begin{array}{c}\text { Bus } \\
\text { Number }\end{array}$ & $\begin{array}{l}\text { Bus } \\
\text { Name }\end{array}$ & $\begin{array}{c}\text { Base } \\
\mathrm{kV}\end{array}$ & $\begin{array}{c}\text { Actual Voltage } \\
(\mathrm{kV})\end{array}$ & $\begin{array}{c}\text { Percentage } \\
\text { (\%) }\end{array}$ & $\begin{array}{c}\text { Voltage } \\
(\mathrm{kV})\end{array}$ & $\begin{array}{c}\text { Percentage } \\
\text { (\%) }\end{array}$ & $\begin{array}{c}\text { Condition } \\
\pm 5 \%\end{array}$ \\
\hline 1 & KB_6.6 & 6.6 & 6.6561 & 100.85 & 6.798 & 103.00 & Normal \\
\hline 101 & SB_6.6 & 6.6 & 6.6561 & 100.85 & 6.897 & 104.50 & Normal \\
\hline 201 & KB_33 & 33 & 31.6602 & 95.94 & 33.3881 & 101.18 & Normal \\
\hline 301 & SB_33 & 33 & 31.6602 & 95.94 & 33.3881 & 101.18 & Normal \\
\hline 401 & SD_33 & 33 & 31.6602 & 95.94 & 33.3881 & 101.18 & Normal \\
\hline 501 & TS_33 & 33 & 31.4292 & 95.24 & 33.1467 & 100.44 & Normal \\
\hline 601 & SM_33 & 33 & 31.3467 & 94.99 & 33.0737 & 100.22 & Normal \\
\hline 701 & BS_33 & 33 & 32.0397 & 97.09 & 33.6592 & 102.00 & Normal \\
\hline 801 & BN_11 & 11 & 11.539 & 104.90 & 11.539 & 104.90 & Normal \\
\hline 901 & KG_33 & 33 & 31.4919 & 95.43 & 33.6752 & 102.05 & Normal \\
\hline 1001 & LD_33 & 33 & 31.4985 & 95.45 & 33.7002 & 102.12 & Normal \\
\hline 1101 & PI_33 & 33 & 31.5117 & 95.49 & 33.8975 & 102.72 & Normal \\
\hline 1201 & MS_33 & 33 & 31.4754 & 95.38 & 33.8718 & 102.64 & Normal \\
\hline 1301 & GN_11 & 11 & 10.5039 & 95.49 & 11.44 & 104.00 & Normal \\
\hline 1401 & SA_33 & 33 & 31.7295 & 96.15 & 34.0495 & 103.18 & Normal \\
\hline 1501 & SR_33 & 33 & 31.6569 & 95.93 & 33.3855 & 101.17 & Normal \\
\hline 1601 & LP_33 & 33 & 31.7295 & 96.15 & 34.0821 & 103.28 & Normal \\
\hline 1701 & LD1_11 & 11 & 10.5765 & 96.15 & 11.539 & 104.90 & Normal \\
\hline 1801 & LD2_11 & 11 & 10.5765 & 96.15 & 11.539 & 104.90 & Normal \\
\hline 1901 & LD3_11 & 11 & 10.5765 & 96.15 & 11.539 & 104.90 & Normal \\
\hline 2001 & LD4_11 & 11 & 10.5765 & 96.15 & 11.539 & 104.90 & Normal \\
\hline 2101 & LK_33 & 33 & 31.6569 & 95.93 & 33.3855 & 101.17 & Normal \\
\hline 2201 & SC_33 & 33 & 31.614 & 95.80 & 34.0326 & 103.13 & Normal \\
\hline 2301 & UB_33 & 33 & 31.614 & 95.80 & 34.0327 & 103.13 & Normal \\
\hline 2401 & BM_33 & 33 & 31.7295 & 96.15 & 34.0495 & 103.18 & Normal \\
\hline 2501 & SD2_33 & 33 & 31.6602 & 95.94 & 33.3881 & 101.18 & Normal \\
\hline
\end{tabular}




\begin{tabular}{cccccccccc}
\hline Bus Name & $\begin{array}{c}\text { Base } \\
(\mathrm{kV})\end{array}$ & $\begin{array}{c}\text { Eterm } \\
(\mathrm{pu})\end{array}$ & Efd (pu) & $\begin{array}{c}\text { Power } \\
\text { (MW) }\end{array}$ & $\begin{array}{c}\text { Reactive } \\
\text { (MVars) }\end{array}$ & $\begin{array}{c}\text { Power } \\
\text { Factor }\end{array}$ & $\begin{array}{c}\text { Angle } \\
\text { (degree) }\end{array}$ & Id (pu) & Iq (pu) \\
\hline KB_6.6 & 6.6 & 1.0301 & 2.1454 & 10.06 & 3.02 & 0.9577 & 3.41 & 0.6008 & 0.4114 \\
SB_6.6 & 6.6 & 1.0446 & 2.4176 & 10.06 & 5.18 & 0.8890 & 8.94 & 0.6742 & 0.3792 \\
BN_11 & 11 & 1.0498 & 2.1639 & 24.79 & 7.81 & 0.9538 & 27.99 & 0.5766 & 0.3954 \\
GN_11 & 11 & 1.0395 & 1.9159 & 17.16 & 2.96 & 0.9855 & 27.01 & 0.5565 & 0.4215 \\
LD1_11 & 11 & 1.0489 & 1.5930 & 9.97 & 2.30 & 0.9744 & 23.47 & 0.2697 & 0.4452 \\
LD2_11 & 11 & 1.0489 & 1.6057 & 10.48 & 2.26 & 0.9775 & 22.46 & 0.2828 & 0.4659 \\
LD3_11 & 11 & 1.0490 & 1.7580 & 15.00 & 1.96 & 0.9916 & 13.80 & 0.4298 & 0.6380 \\
LD3_11 & 11 & 1.0490 & 1.7580 & 15.00 & 1.96 & 0.9916 & 13.80 & 0.4298 & 0.6380 \\
\hline
\end{tabular}

Figure 2. Initial condition of machines.

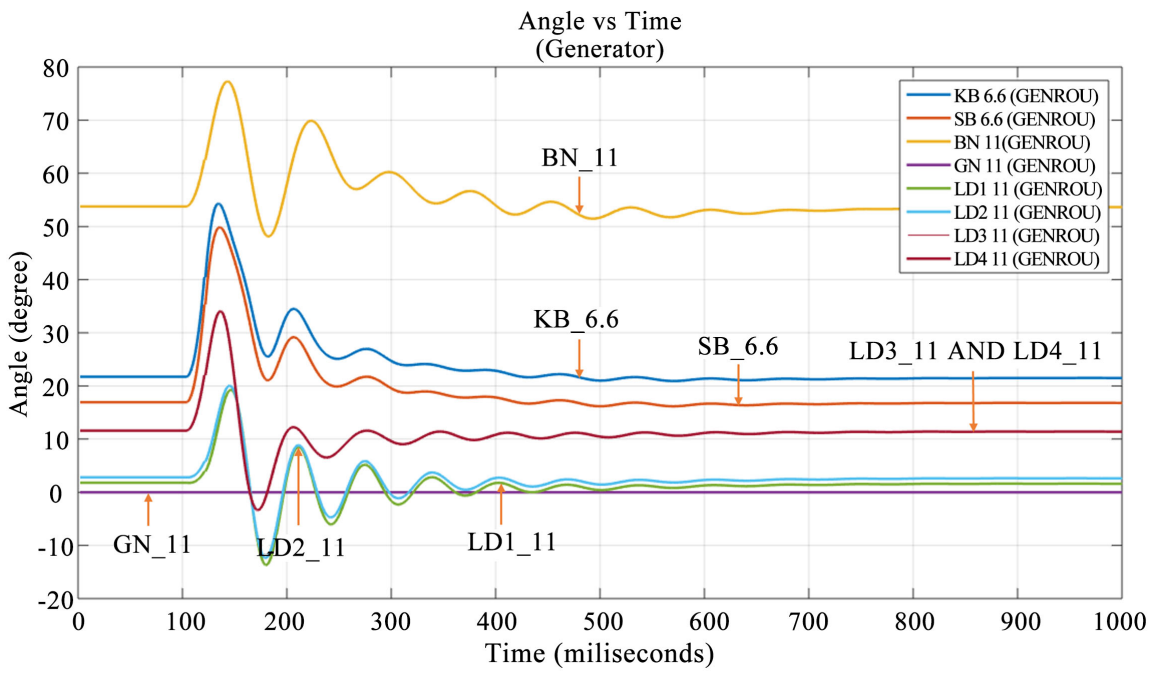

Figure 3. Swing rotor angle vs time for generators.

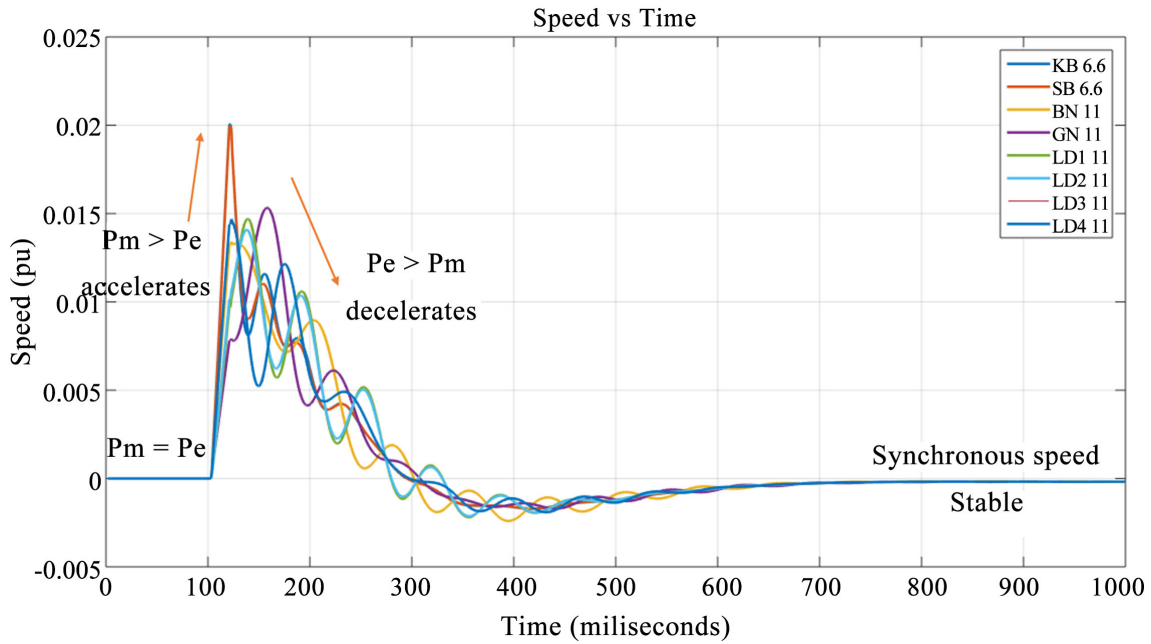

Figure 4. Impulse response of speed vs time for machines. 


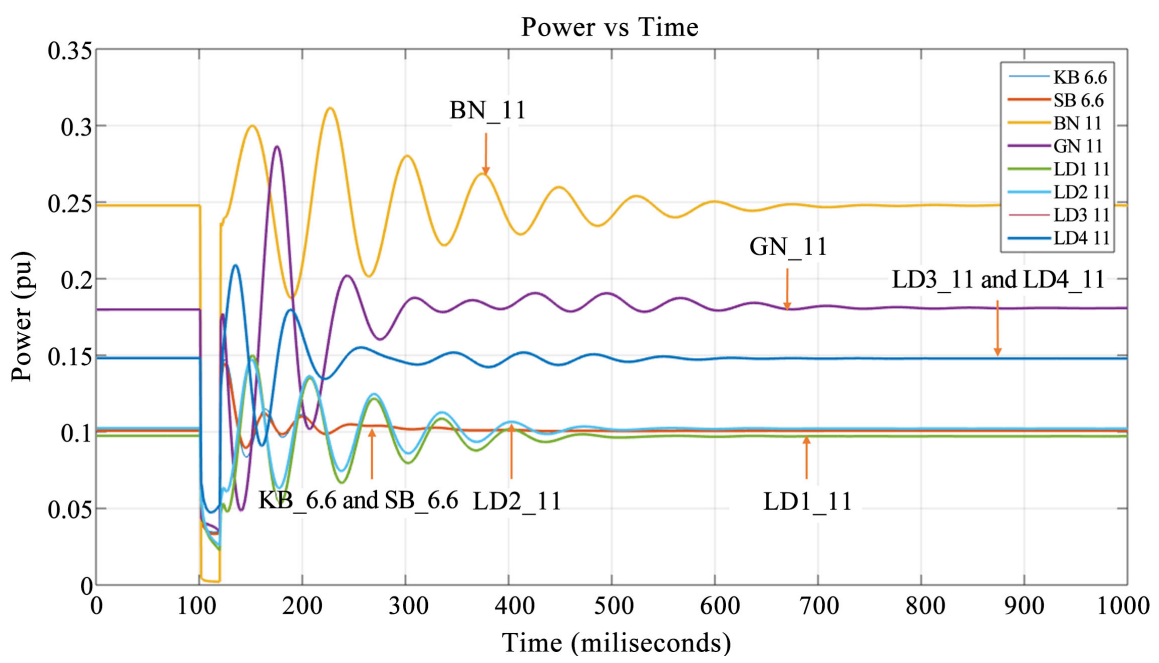

Figure 5. Active power vs time for machines.

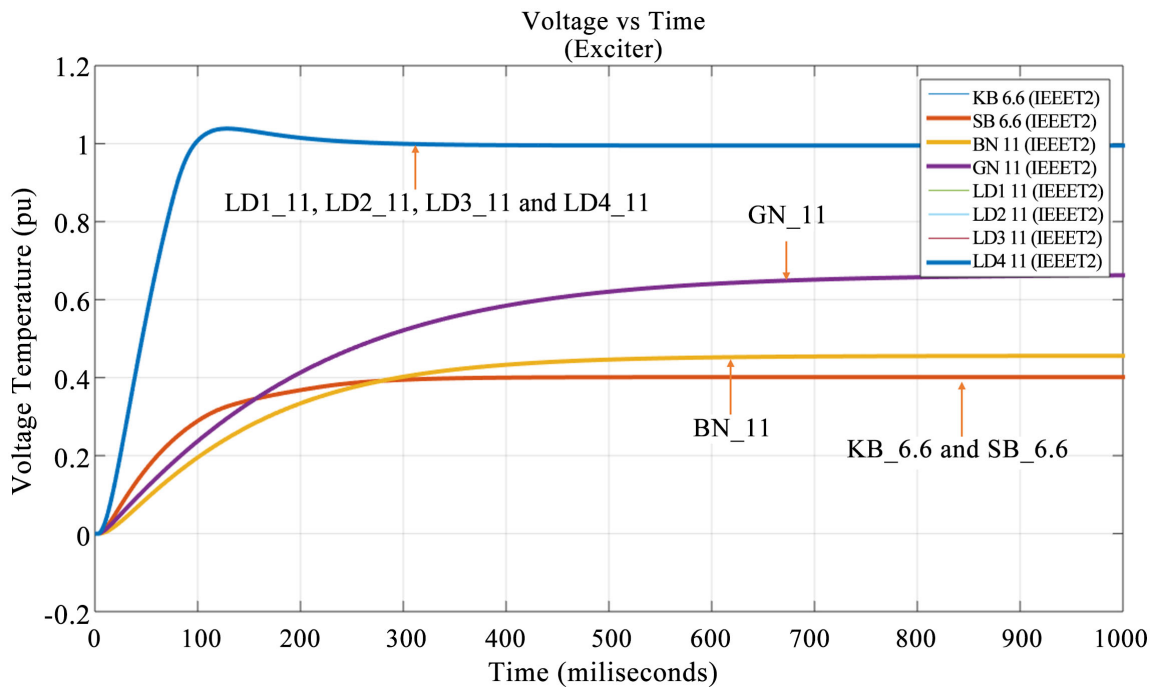

Figure 6. Terminal voltage vs time for exciters.

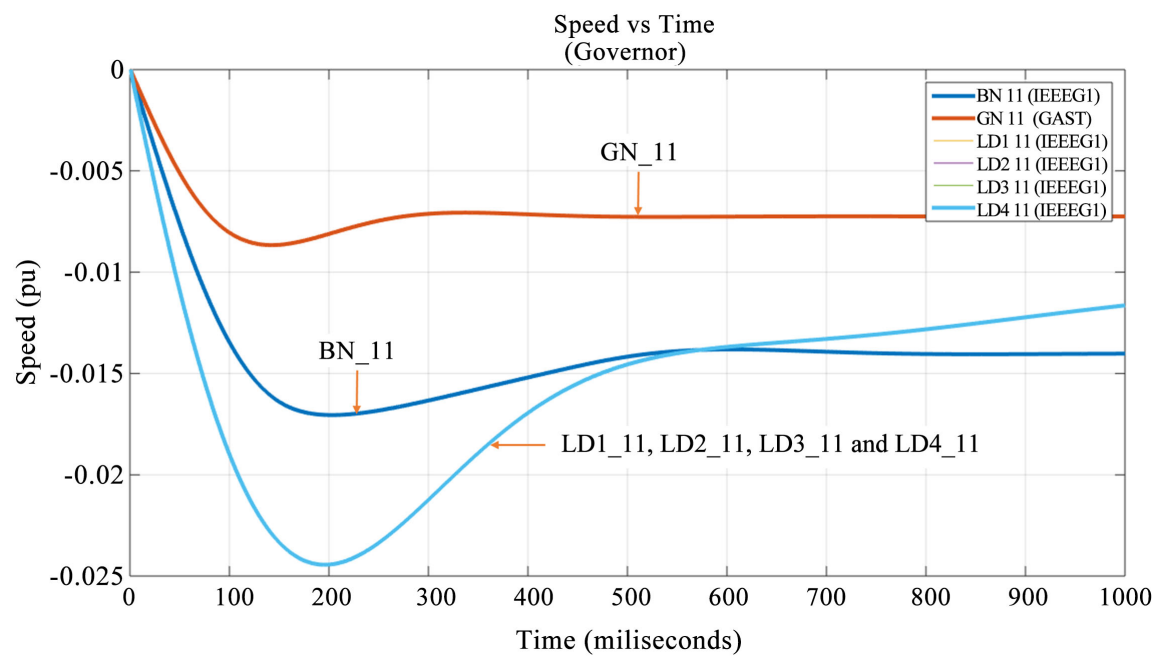

Figure 7. Step response of speed vs time for governors. 


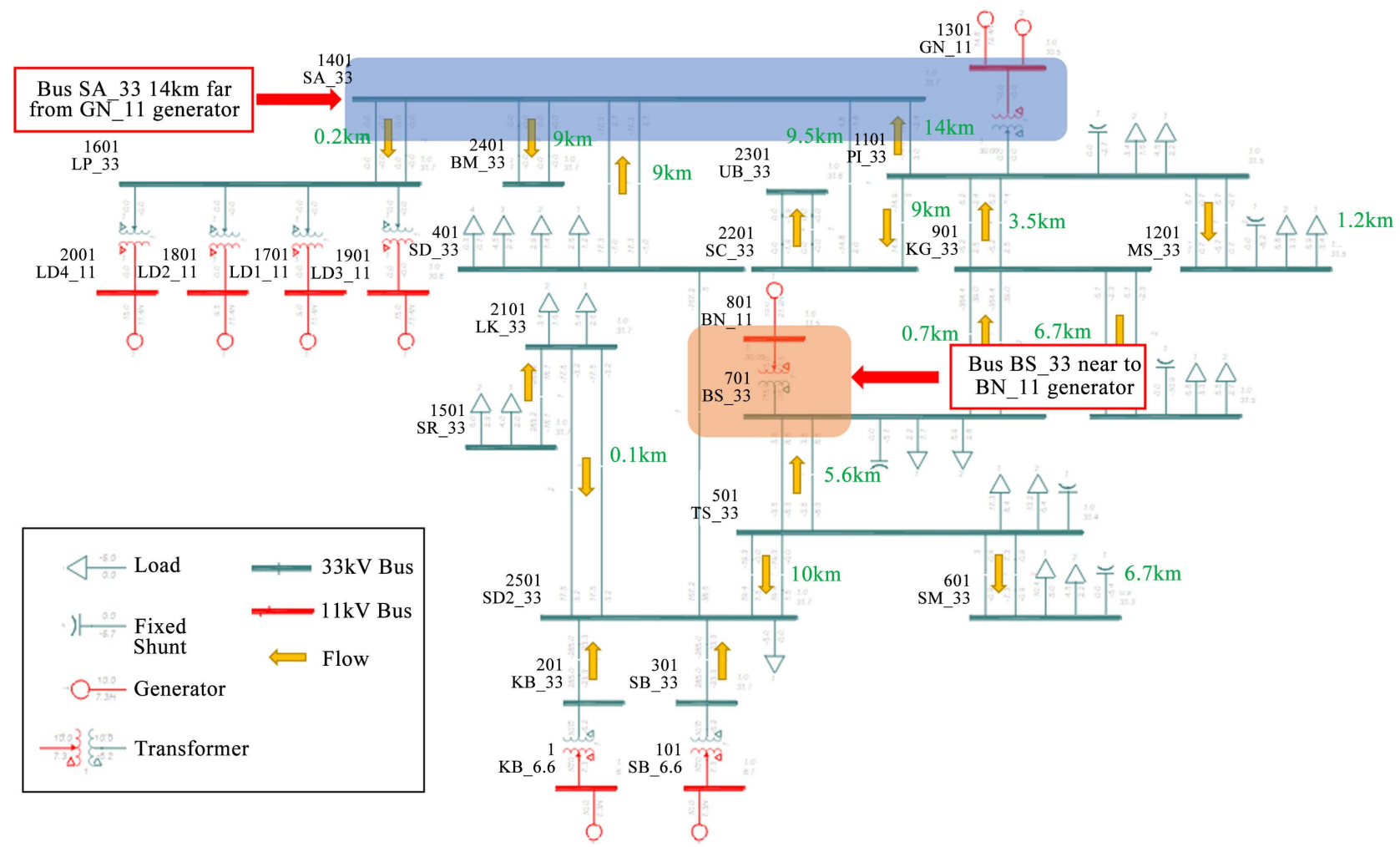

Figure 8. Bus near and far from generator.

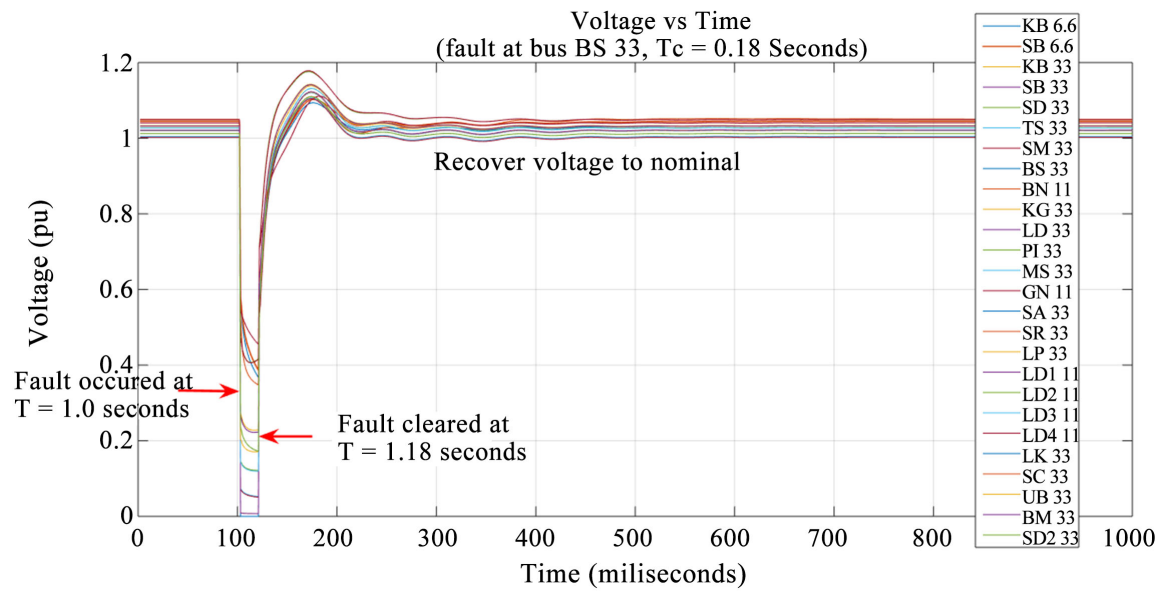

Figure 9. Voltage vs Time when faulted at bus BS_33.

With the fault cleared at time $=1.18$ seconds, the electrical power becomes low but the rotor still running above synchronous speed, hence the angle and the electrical power continue to increase. When the electrical power is greater than mechanical power $(\mathrm{Pe}>\mathrm{Pm})$, it causing the rotor to decelerate toward synchronous speed until the angle reaches its critical value. When the system reached the critical value, the rotor angle will continue to oscillate back and forth at its natural frequency until it becomes stable.

In running the simulation the time of fault clear is from breaker open until 10 seconds. 


\subsection{Exciter}

The results of the excitation system response in Figure 6, steady-state value for LD1_11, LD2_11, LD3_11 and LD4_11 are 0.994996 pu (terminal voltage). Steady-state value for GN_11 is $0.662346 \mathrm{pu}$ (terminal voltage). Steady-state value for BN_11 is $0.455770 \mathrm{pu}$ (terminal voltage). Steady-state value for KB_6.6 and SB_6.6 are $0.401253343 \mathrm{pu}$ (terminal voltage).

Based on the results in Figure 6 indicate that GN_11, BN_11, KB_6.6 and SB_6.6 exciters perform slower than LD1_11, LD2_11, LD3_11 and LD4_11 exciters which are this exciter meet the $1 \mathrm{pu}$ the excitation system voltage requirement. These bus conditions are shown in Table 9.

\subsection{Governor}

Figure 7 shows the variation of speed with time for governor IEEEG1 and GAST types. All final frequencies were determined by the droop, $\mathrm{R}$ of the responding governors, Table 10. The frequency drops depends upon the generator inertia values. The least frequency deviation occurs with high inertia and fast governors. Governor condition are given in Table 11.

\subsection{Critical Clearing Time (Result)}

To determine the critical clearing time when the fault occurs at bus that close and far from generator, refer to Figure 8. It shows that bus BS_33 is near to generator BN_11, while for bus SA_33 is 14 kilometers far from generator GN_11.

Figure 9 and Figure 10 have been obtained by the technique of trial and error method in order to determining the critical clearing time of the system where the fault duration was increased gradually using the step time of $\Delta t=0.01$ seconds until the system appears to be unstable by observing machine's rotor angle as a reference point.

Figure 9 shows the variation of voltage with time for a three phase fault applied on bus BS_33 (bus near to generator). Since the three phase fault applied at time $=1.0$ seconds, then the fault is clear at time $=1.18$ seconds. Thus, the critical clearing time is 0.18 seconds and the system becomes stable.

Figure 10 shows the variation of voltage with time for a three phase fault applied on bus SA_33 (bus far from generator). Since the three phase fault applied at time $=1.0$ seconds, then the fault is clear at time $=1.23$ seconds. Thus, the critical clearing time is 0.23 seconds and the system becomes stable.

It can be seen that transient stability is greatly affected by the location of a fault from bus to generator. Table 12 shows the critical clearing times in seconds determined for all the twenty-six buses on the Sandakan Power Grid.

Transient stability analysis is run starting with a clearing time of 0.01 seconds. If the system is proved a stable condition, another analysis run is made by increasing the clearing time higher than first run. If the second run is still in stable condition, then more runs are made until the system becomes unstable. If the run showed an unstable system, then the clearing time of previous run gives the desired result. 


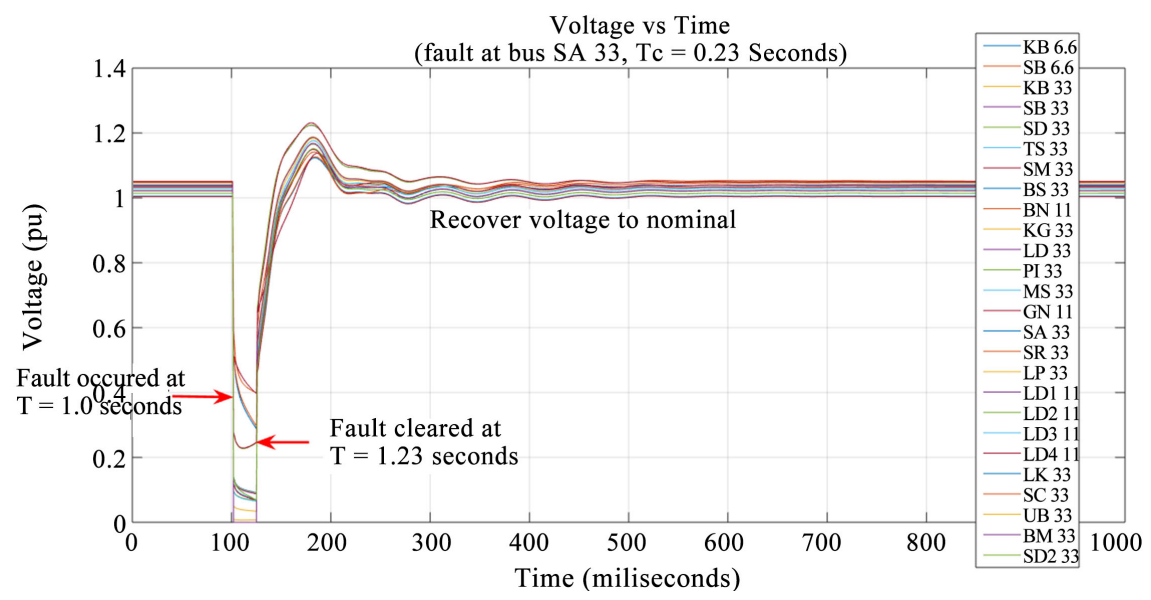

Figure 10. Voltage vs Time when faulted at bus SA_33.

Table 9. Exciter conditions.

\begin{tabular}{cl}
\hline Exciter & Condition \\
\hline KB_6.6 (IEEET2) & Slow exciter \\
SB_6.6 (IEEET2) & \\
BN_11 (IEEET2) & Slow exciter \\
GN_11 (IEEET2) & Slow exciter \\
LD1_11 (IEEET2) & \\
LD2_11 (IEEET2) & Fast exciter \\
LD3_11 (IEEET2) & \\
LD4_11 (IEEET2) & \\
\hline
\end{tabular}

Table 10. Steady-state of governor.

\begin{tabular}{cccccc}
\hline \multicolumn{5}{c}{ Steady state } \\
\hline Governor & Base frequency (Hz) & Speed (pu) & Frequency (Hz) & Droop (R) & Inertia (H) \\
\hline BN_11 (IEEEG1) & 50 & -0.01402 & 49.299 & $\mathrm{R}=0.1$ & 4.68 \\
GN_11 (GAST) & 50 & -0.00725 & 49.6375 & $\mathrm{R}=0.05$ & 6.70 \\
LD1_11 & & & & & \\
LD2_11 & 50 & -0.00808 & 49.596 & $\mathrm{R}=0.0556$ & 3.19 \\
LD3_11 & & & & & \\
LD4_11 (IEEEG1) & & & & & \\
\hline
\end{tabular}

Table 11. Governor conditions.

\begin{tabular}{cc}
\hline Governor & Condition \\
\hline BN_11 (IEEEG1) & High inertia and fast governor \\
GN_11 (GAST) & High inertia and fast governor \\
LD1_11 (IEEEG1) & \\
LD2_11 (IEEEG1) & Low inertia and slow governor \\
LD3_11 (IEEEG1) & \\
LD4_11 (IEEEG1) & \\
\hline
\end{tabular}


Table 12. Critical clearing time with different location.

\begin{tabular}{|c|c|c|}
\hline Fault at bus & Clearing time, Tc (seconds) & Location from Generator \\
\hline KB_6.6 & 0.05 & Near \\
\hline SB_6.6 & 0.05 & Near \\
\hline KB_33 & 0.10 & Near \\
\hline SB_33 & 0.10 & Near \\
\hline SD_33 & 0.15 & Near \\
\hline TS_33 & 0.18 & Far \\
\hline SM_33 & 0.19 & Far \\
\hline BS_33 & 0.18 & Far \\
\hline BN_11 & 0.10 & Near \\
\hline KG_33 & 0.18 & Far \\
\hline LD_33 & 0.18 & Far \\
\hline PI_33 & 0.19 & Far \\
\hline MS_33 & 0.21 & Far \\
\hline GN_11 & 0.10 & Near \\
\hline SA_33 & 0.23 & Far \\
\hline SR_33 & 0.17 & Far \\
\hline LP_33 & 0.16 & Far \\
\hline LD1_11 & 0.10 & Near \\
\hline LD2_11 & 0.10 & Near \\
\hline LD3_11 & 0.10 & Near \\
\hline LD4_11 & 0.10 & Near \\
\hline LK_33 & 0.15 & Near \\
\hline SC_33 & 0.17 & Far \\
\hline UB_33 & 0.17 & Far \\
\hline BM_33 & 0.17 & Far \\
\hline SD2_33 & 0.13 & Near \\
\hline
\end{tabular}

\section{Conclusion}

This paper presents a modeling and simulating case data of 26 buses, 8 generators and 22 loads $33 \mathrm{kV}$ power grid that in service mode. Through load flow analysis, the voltage performance under different conditions can be determined. The desired analysis of the transient stability of the system based on output values such as machine rotor angle, electrical power, machine speed and bus voltage were found to be stable after fault is cleared. The rotor angle, power, speed and the voltage in the grid system is back to its normal condition where there is no generator set that will out of phase and when the fault is cleared. The theory of the critical clearing time (CCT) when the fault occurs close and far from the generator was proved in this paper by using trial and error method. Thus, as the 
distance between the bus and the generator increases, the critical clearing time also increases.

\section{References}

[1] Kundur, P. (1994). Power System Stability and Control. In: Lauby, N.J., Ed., Methods of Improving Stability, McGraw-Hill Inc., p. 1104.

[2] Kundur, P., et al. (2004) Definition and Classification of Power System Stability. IEEE Transactions on Power Systems, 19, 1387-1401.

https://doi.org/10.1109/TPWRS.2004.825981

[3] Hooda, P.R. (2012) Transient Stability Analysis of Power System Using Matlab. International Journal of Engineering Sciences and Research Technology (IJESRT).

[4] Ren, L.-Y., Fang, T., Yan, J.-F., Yu, Z.-H., Su, F. and Wu, T. (2012) Online Application and Fast Solving Method for Critical Clearing Time of Three-Phase Short Circuit in Power System. International Journal of Smart Grid and Clean Energy, 2, 93-99.

[5] Mohamad, A.M., Hashim, N., Hamzah, N., Ismail, N.F.N. and Latip, M.F.A. (2011) Transient Stability Analysis on Sarawak's Grid using Power System Simulator for Engineering (PSS/E). IEEE Symposium on Industrial Electronics and Application (IEA), Langkawi, 25-28 September 2011, 521-526.

[6] Barsoum, N., Asok, C.B., Kwong, D.T.S. and Kit, C.G.T. (2017) Power Analysis for a Limited Bus Grid System with Distribution Generators. Global Journal of Technology and Optimization, OMICS Online, 8, 1-10.

[7] Barsoum, N. and Lee, C.Z. (2013) Simulation of Power Flow and Protection of a Limited Bus Grid System with Injected Solar Power. Journal of Energy and Power Engineering EPE, Scientific Research on Optimization, 5, 59-69. 


\section{Appendix}

Table I. Buses data used in PSS/E.

\begin{tabular}{|c|c|c|c|c|c|}
\hline Bus No. & Bus Name & Bus Code & Base $\mathrm{kV}$ & Voltage (pu) & Angle (deg) \\
\hline 1 & KB_6.6 & -2 & 6.6 & 1.0085 & -15.28 \\
\hline 2 & SB_6.6 & -2 & 6.6 & 1.0085 & -15.28 \\
\hline 3 & SB_33 & 1 & 33.0 & 0.9594 & -19.51 \\
\hline 4 & KB_33 & 1 & 33.0 & 0.9594 & -19.51 \\
\hline 5 & SD_33 & 1 & 33.0 & 0.9594 & -19.51 \\
\hline 6 & TS_33 & 1 & 33.0 & 0.9524 & -23.99 \\
\hline 7 & SM_33 & 1 & 33.0 & 0.9499 & -24.28 \\
\hline 8 & BS_33 & 1 & 33.0 & 0.9709 & -23.60 \\
\hline 9 & KG_33 & 1 & 33.0 & 0.9543 & -25.46 \\
\hline 10 & LD_33 & 1 & 33.0 & 0.9545 & -25.73 \\
\hline 11 & PI_33 & 1 & 33.0 & 0.9549 & -24.88 \\
\hline 12 & MS_33 & 1 & 33.0 & 0.9538 & -25.07 \\
\hline 13 & TR_33 & 4 & 33.0 & 1.0000 & 0.00 \\
\hline 14 & SA_33 & 1 & 33.0 & 0.9615 & -23.11 \\
\hline 15 & SR_33 & 1 & 33.0 & 0.9593 & -19.52 \\
\hline 16 & LP_33 & 1 & 33.0 & 0.9615 & -23.11 \\
\hline 17 & LK_33 & 1 & 33.0 & 0.9593 & -19.52 \\
\hline 18 & SC_33 & 1 & 33.0 & 0.9580 & -24.01 \\
\hline 19 & UB_33 & 1 & 33.0 & 0.9580 & -24.01 \\
\hline 20 & BM_33 & 1 & 33.0 & 0.9615 & -23.11 \\
\hline 21 & SI_33 & 4 & 33.0 & 1.0000 & 0.00 \\
\hline 22 & KG_11 & 4 & 11.0 & 1.0000 & 0.00 \\
\hline 23 & GN_11 & 2 & 11.0 & 0.9549 & -54.88 \\
\hline 24 & SG2_11 & 4 & 11.0 & 1.0000 & 0.00 \\
\hline 25 & SG1_11 & 4 & 11.0 & 1.0000 & 0.00 \\
\hline 26 & SD2_33 & 1 & 33.0 & 0.9594 & -19.51 \\
\hline 27 & BS_33 & 4 & 33.0 & 1.0000 & 0.00 \\
\hline 28 & BN_11 & 2 & 11.0 & 1.0490 & 10.42 \\
\hline 29 & LD1_11 & 2 & 11.0 & 0.9615 & -23.11 \\
\hline 30 & BG_33 & 4 & 33.0 & 1.0000 & 0.00 \\
\hline 31 & B8_11 & 4 & 11.0 & 1.0000 & 0.00 \\
\hline 32 & LD2_11 & 2 & 11.0 & 0.9615 & -23.11 \\
\hline 33 & LD3_11 & 2 & 11.0 & 0.9615 & -23.11 \\
\hline 34 & LD4_11 & 2 & 11.0 & 0.9615 & -23.11 \\
\hline
\end{tabular}


Table II. Transformer branch data used in PSS/E.

\begin{tabular}{|c|c|c|c|c|c|c|}
\hline \multicolumn{5}{|c|}{ Transformer Branches } & \multirow{3}{*}{ Tap Positions } & \multirow{3}{*}{$\begin{array}{c}\text { Winding MVA } \\
\text { Base }\end{array}$} \\
\hline \multicolumn{2}{|c|}{ From Bus } & \multicolumn{2}{|c|}{ To Bus } & \multirow{2}{*}{ Id } & & \\
\hline No & Name & No & Name & & & \\
\hline 1 & KB_6.6 & 4 & KB_33 & 1 & 8 & 14.0 \\
\hline 2 & SB_6.6 & 3 & SB_33 & 1 & 8 & 14.0 \\
\hline 8 & BS_33 & 28 & BN_11 & 1 & 5 & 25.0 \\
\hline 11 & PI_33 & 23 & GN_11 & 1 & 13 & 20.0 \\
\hline 16 & LP_33 & 29 & LD1_11 & 1 & 5 & 20.0 \\
\hline 16 & LP_33 & 32 & LD2_11 & 1 & 5 & 20.0 \\
\hline 16 & LP_33 & 33 & LD3_11 & 1 & 5 & 20.0 \\
\hline 16 & LP_33 & 34 & LD4_11 & 1 & 5 & 20.0 \\
\hline
\end{tabular}

Table III. Machines data used in PSS/E.

\begin{tabular}{|c|c|c|c|c|c|c|c|c|}
\hline $\begin{array}{l}\text { Bus } \\
\text { No. }\end{array}$ & $\begin{array}{c}\text { Bus } \\
\text { Name }\end{array}$ & $\begin{array}{l}\text { Bus } \\
\text { Code }\end{array}$ & PGen (MW) & $\begin{array}{c}\mathrm{P}_{\mathrm{Max}} \\
(\mathrm{MW})\end{array}$ & $\begin{array}{c}\mathrm{P}_{\mathrm{Min}} \\
(\mathrm{MW})\end{array}$ & $\begin{array}{l}\text { QGen } \\
\text { (Mvar) }\end{array}$ & $\begin{array}{c}\mathrm{Q}_{\mathrm{Max}} \\
(\mathrm{Mvar})\end{array}$ & $\begin{array}{c}\mathrm{Q}_{\text {Min }} \\
\text { (Mvar) }\end{array}$ \\
\hline 1 & KB_6.6 & 2 & 10.00 & 10.0 & 0.0 & 7.31 & 7.31 & 0.50 \\
\hline 2 & SB_6.6 & 2 & 10.00 & 10.0 & 0.0 & 7.31 & 7.31 & 0.50 \\
\hline 23 & GN_11 & 2 & 14.76 & 19.0 & 10.0 & 12.39 & 12.39 & -7.35 \\
\hline 23 & GN_11 & 2 & 15.00 & 18.0 & 10.0 & 8.56 & 12.39 & -7.35 \\
\hline 24 & SG2_11 & 4 & 25.00 & 10.0 & 0.0 & -3.003 & 7.00 & -5.00 \\
\hline 25 & SG1_11 & 4 & 25.00 & 10.0 & 0.0 & 1.525 & 7.00 & -5.00 \\
\hline 28 & BN_11 & 2 & 15.00 & 20.0 & 0.0 & 17.468 & 21.24 & -5.22 \\
\hline 29 & LD1_11 & 2 & 9.00 & 15.0 & 8.0 & 6.648 & 11.40 & -8.50 \\
\hline 32 & LD2_11 & 2 & 9.50 & 15.0 & 8.0 & 6.603 & 11.40 & -8.50 \\
\hline 33 & LD3_11 & 2 & 15.00 & 15.0 & 8.0 & 10.185 & 11.40 & -8.50 \\
\hline 34 & LD4_11 & 2 & 15.00 & 15.0 & 8.0 & 7.224 & 11.40 & -8.50 \\
\hline
\end{tabular}

Table IV. Load data used in PSS/E.

\begin{tabular}{ccccc}
\hline Bus No. & Bus Name & Id & P load $_{1}(\mathrm{MW})$ & Q $_{\text {load }}($ Mvar $)$ \\
\hline 5 & SD_33 & 1 & 2.5730 & 1.2460 \\
5 & SD_33 & 2 & 2.8790 & 1.3950 \\
5 & SD_33 & 3 & 4.4600 & 2.1600 \\
5 & SD_33 & 4 & 0.2820 & 0.1360 \\
6 & TS_33 & 1 & 17.2890 & 8.3730 \\
6 & TS_33 & 2 & 13.1720 & 6.3790 \\
7 & SM_33 & 1 & 10.4150 & 5.0440 \\
7 & SM_33 & 2 & 4.4720 & 2.1660 \\
8 & BS_33 & 1 & 2.1810 & 1.0560 \\
\hline
\end{tabular}


N. Barsoum et al.

\section{Continued}

\begin{tabular}{lllll}
\hline 8 & BS_33 & 2 & 5.8810 & 2.8480 \\
8 & BS_33 & 3 & 0.0000 & 0.0000 \\
10 & LD_33 & 1 & 6.8490 & 3.3170 \\
10 & LD_33 & 2 & 5.5260 & 2.6760 \\
11 & PI_33 & 1 & 4.4970 & 2.1780 \\
11 & PI_33 & 2 & 3.3820 & 1.6380 \\
12 & MS_33 & 1 & 6.9470 & 3.3650 \\
12 & MS_33 & 2 & 6.8490 & 3.3170 \\
15 & SR_33 & 1 & 4.0310 & 1.9520 \\
15 & SR_33 & 2 & 6.0410 & 2.9260 \\
17 & LK_33 & 1 & 5.4160 & 2.6230 \\
17 & LK_33 & 2 & 3.3570 & 1.6260 \\
26 & SD2_33 & 99 & -5.0000 & 0.0000 \\
27 & BS_33 & 99 & -10.0000 & 0.0000 \\
30 & BG_33 & 99 & -2.0000 & 0.0000 \\
\hline
\end{tabular}

Table V. Branch/Distribution line data used in PSS/E.

\begin{tabular}{|c|c|c|c|c|c|c|c|c|}
\hline \multicolumn{5}{|c|}{ Distribution Branches } & \multirow{3}{*}{$\begin{array}{l}\text { RATE1 } \\
\text { (MVA) }\end{array}$} & \multirow{3}{*}{$\begin{array}{c}\text { Length } \\
\text { (mile) }\end{array}$} & \multirow{3}{*}{ Line R (pu) } & \multirow{3}{*}{ Line $X(p u)$} \\
\hline \multicolumn{2}{|c|}{ From Bus } & \multicolumn{2}{|c|}{ To Bus } & \multirow{2}{*}{ Id } & & & & \\
\hline No & Name & No & Name & & & & & \\
\hline 3 & SB_33 & 26 & SD2_33 & 1 & 36.0 & 36.0 & 0.000000 & 0.000100 \\
\hline 4 & KB_33 & 26 & SD2_33 & 2 & 36.0 & 36.0 & 0.000000 & 0.000100 \\
\hline 5 & SD_33 & 14 & SA_33 & 1 & 36.0 & 9.0 & 0.017631 & 0.333357 \\
\hline 5 & SD_33 & 14 & SA_33 & 2 & 36.0 & 9.0 & 0.017631 & 0.333357 \\
\hline 5 & SD_33 & 26 & SD2_33 & 1 & 36.0 & 36.0 & 0.000000 & 0.000100 \\
\hline 6 & TS_33 & 7 & SM_33 & 1 & 35.5 & 6.7 & 0.024425 & 0.065831 \\
\hline 6 & TS_33 & 7 & SM_33 & 2 & 35.5 & 6.7 & 0.024425 & 0.065831 \\
\hline 6 & TS_33 & 8 & BS_33 & 1 & 18.0 & 5.6 & 0.010970 & 0.207422 \\
\hline 6 & TS_33 & 8 & BS_33 & 2 & 18.0 & 5.6 & 0.010970 & 0.207422 \\
\hline 6 & TS_33 & 26 & SD2_33 & 1 & 36.0 & 10.0 & 0.019590 & 0.370397 \\
\hline 6 & TS_33 & 26 & SD2_33 & 2 & 36.0 & 10.0 & 0.019590 & 0.370397 \\
\hline 8 & BS_33 & 9 & KG_33 & 1 & 32.6 & 0.7 & 0.005039 & 0.007713 \\
\hline 8 & BS_33 & 9 & KG_33 & 2 & 32.6 & 0.7 & 0.005039 & 0.007713 \\
\hline 9 & KG_33 & 10 & LD_33 & 1 & 43.7 & 6.7 & 0.020426 & 0.062755 \\
\hline 9 & KG_33 & 10 & LD_33 & 2 & 43.7 & 6.7 & 0.020426 & 0.062755 \\
\hline 9 & KG_33 & 11 & PI_33 & 1 & 18.0 & 3.5 & 0.059158 & 0.125699 \\
\hline 9 & KG_33 & 11 & PI_33 & 2 & 18.0 & 3.5 & 0.059158 & 0.125699 \\
\hline 11 & PI_33 & 12 & MS_33 & 1 & 18.0 & 1.2 & 0.020283 & 0.043097 \\
\hline
\end{tabular}




\section{Continued}

\begin{tabular}{lllllllll}
\hline 11 & PI_33 & 12 & MS_33 & 2 & 18.0 & 1.2 & 0.020283 & 0.043097 \\
11 & PI_33 & 14 & SA_33 & 1 & 35.5 & 14.0 & 0.051038 & 0.137557 \\
11 & PI_33 & 18 & SC_33 & 1 & 35.5 & 9.0 & 0.032810 & 0.088430 \\
12 & MS_33 & 27 & BS_33 & 1 & 0.0 & 36.0 & 0.000000 & 0.000100 \\
14 & SA_33 & 16 & LP_33 & 1 & 18.0 & 0.2 & 0.003380 & 0.007183 \\
14 & SA_33 & 16 & LP_33 & 2 & 18.0 & 0.2 & 0.003380 & 0.007183 \\
14 & SA_33 & 18 & SC_33 & 1 & 35.5 & 9.5 & 0.034633 & 0.093343 \\
14 & SA_33 & 20 & BM_33 & 1 & 35.5 & 9.0 & 0.032810 & 0.088430 \\
14 & SA_33 & 20 & BM_33 & 2 & 35.5 & 9.0 & 0.032810 & 0.088430 \\
15 & SR_33 & 17 & LK_33 & 1 & 36.0 & 0.0 & 0.000000 & 0.000100 \\
17 & LK_33 & 26 & SD2_33 & 1 & 35.5 & 0.1 & 0.000365 & 0.000983 \\
17 & LK_33 & 26 & SD2_33 & 2 & 35.5 & 0.1 & 0.000365 & 0.000983 \\
18 & SC_33 & 19 & UB_33 & 1 & 35.5 & 0.0 & 0.000000 & 0.000100 \\
18 & SC_33 & 19 & UB_33 & 2 & 35.5 & 0.0 & 0.000000 & 0.000100 \\
\hline
\end{tabular}

